\title{
PSychological CAPITAL, a ReQUisite for ORganisational Performance in South AFrica
}

\author{
Yvonne du Plessis and Nicolene Barkhuizen
}

Department of Human Resource Management, University of Pretoria

Accepted: August 2011

\begin{abstract}
Scholars argue that to address the social, economic and political challenges facing South Africa since 1994, organisational managers/leaders should adopt a positive approach, based on sound organisational behaviour. This study administered the Psychological Capital Questionnaire (PCQ) to determine whether human resources practitioners $(\mathrm{N}=131)$ as custodians of change and positive behaviour in organisations in South Africa embrace core elements of Positive Organisational Behaviour (POB). Exploratory factor analysis resulted in a three-factor model for the PCQ, renamed the Potential South African PsyCap (PSAPsyCap) instrument. All dimensions displayed acceptable reliabilities. Statistically significant differences exist in the $\mathrm{POB}$ of demographic groups, relating to age, marital status, home language, seniority and qualifications. This research reveals that South African HR practitioners and managers should fully embrace psychological capital to effectively create caring workplaces taking cognizance of the broader economic and social issues affecting employees and their performance.
\end{abstract}

Key words: psychological capital, positive psychology, Human Resource practitioner, employee performance

JEL: D23, M12, 015

\section{1}

\section{Introduction}

The current global economic turmoil has contributed to a host of problems in the workplace, including social issues like unemployment, fears of job losses, hopelessness and general pessimism. In order to turn this situation around, a positive mindset in organisations is needed. Positively oriented popular bestsellers are capitalizing on this state of affairs, but what are scientific researchers, organisational behaviour (OB) specialists, change agents and management doing to achieve positively oriented research and practice to facilitate real care in today's often depressed workplaces? Based on seminal research of Seligman, Luthans (2002) encouraged researchers to focus their efforts on the real world, where popular motivational bestsellers tend to adopt a positive approach. Strümpfer (2005) and Roberts (2006) also support a shift towards a positive approach in organisations, referring to a 'strengths perspective' which may generate distinctive value and may contribute to a better understanding of optimal human performance in situations that due to their complexity pose stressful challenges. The complex issues in South Africa cause such stressors.

The positive focus in psychology advocated by Seligman and Csikszentmihalyi (2000) has resulted in a paradigm shift in the practice of and research in psychology, which has in turn inspired the work of Luthans (2002) and his colleagues (Avolio \& Luthans, 2006; Luthans, Avey, Avolio, Norman \& Combs, 2006; Luthans, Youssef \& Avolio, 2007). They have brought a positive focus to organisational behaviour in what has been labelled positive organisational behaviour (POB). POB refers to a positive approach in scrutinizing desired behaviour in the workplace and may be considered to be the first step in building much-needed bridges across the divide between popular literature and scientific knowledge (Luthans, 2002). This conduit in itself is a challenge for social researchers and human resources (HR) practitioners who are the custodians of social issues and change agents in organisations.

The development of positive organisational behaviour (POB) has been demonstrated to 
have a significant impact on employee outputs and a direct impact on organisations' bottom line. Luthans, Youssef and Avolio (2007) acknowledge that this performance orientation and its bottom line relevance warrant attention to it in both public and private organisations.

The main aim of this exploratory study is to determine whether human resources practitioners and managers in South Africa do embrace the core elements of POB, as depicted in the psychological capital (PsyCap) measure developed by Luthans and colleagues, the PsyCap questionnaire (PCQ).

This research is based on the premise that the practice of POB can have a positive impact on reconciliation and organisational performance and that it is especially valuable in the context of a new democracy and in the contemporary diverse society in South Africa. Another assumption is the belief that psychological capital, which is comprised of POB components, is a state-like, rather than a trait-like, order of construct (Luthans, Youssef \& Avolio, 2007). This implies that POB constructs, and therefore psychological capital, are measurable at different levels in a person and can thus be developed. The contrasting trait-based reasoning holds that a person is simply born with or without a specific personality factor, and that such a personality factor cannot be developed in any way.

The implications of the POB approach are particularly significant in the South African organisational environment, where the emphasis is increasingly on the development of equality, cross-cultural relationships, skills and competencies. To date, few empirical scientific studies have assessed or explored POB or psychological capital, and/or its significance for the current South African context. Luthans, Van Wyk and Walumba (2004) advocate a positive approach to South African organisational leadership, one that is embedded within the psychological capacity of hope.

POB is an exciting and relatively new research area worthy of further investigation around the globe. According to Seligman and Csikszentmihalyi (2000), among scholars, employers and employees alike, there is a desire for knowledge of what makes life worth living, and what constitutes quality of life at work or its development. Organisations can add future value to their performance by leveraging positive human competence. The development of such competence could play an important role in organisations' ability to compete effectively. Hence, given the limited availability of empirical knowledge on the topic there is a real need to expand the present body of knowledge. This research therefore attempts to contribute to the existing body of knowledge on POB. It expands on the psychological capital construct and its applicability to HR practitioners as custodians of positive organisational behaviour, change and social well-being in organisations, particularly in the diverse South African context.

At present, in South African organisations, whether private or public, the role of especially the master HR practitioner and HR manager is seen to be that of a change agent and custodian of employee well-being (Du Plessis \& Barkhuizen, 2011). Managers and organisational leaders also have to play a positive role and have to exhibit POB, but, in most cases, it is the HR manager and practitioner in particular who must drive and ensure behavioural change implementation. If the HR practitioner and manager do not exhibit POB, as measured in the PCQ or a derivative thereof, it is likely that the change needed to ensure optimal performance in this new democracy with all its complexities may not be achieved. In order to embrace POB, a positive paradigm is vital.

\section{2}

\section{The positive paradigm}

Traditionally organisational theories have been negatively oriented to some degree. Such "negative" approaches include a focus on counterproductive elements such as stress, ineffective leadership, destructive conflict, unethical behaviour and dysfunctional attitudes and behaviours which have been extensively documented and researched. Luthans (2002) argues that, the organisational behaviour field has paid relatively more attention to managerial and employee dysfunction and problems in the workplace, investigating 'what went wrong' instead of exploring 'what went right $^{6}$. He emphasises that this negative approach has contributed considerably to the generalised lack of truly superior performance, 
continuous development and learning, and proactive strategic change and adaptation required for success.

It is important to question to what extent South Africa's new democracy would be affected or limited by the old negative paradigm. Peterson and Seligman's (2004) classification of character strengths and virtues and development of the Virtues In Action Scale (VIA) intended as positive psychology's equivalent to the Diagnostic and Statistical Manual (DSM) (re)claiming the study of character as a legitimate topic of psychological inquiry and informed societal discourse. This is an attempt at a radical change of the current (largely negative and problem-based) paradigm to a more positive approach to facilitate organisational performance in an emerging economy and in a new democracy such as South Africa.

According to Strümpfer (2005), it has gradually become clearer to many clinicians and members of other sub-disciplines studying organisational behaviour that normal and supernormal functioning cannot be understood within a purely problem-oriented framework. Roberts (2006) points out that if the focus is only on identifying and overcoming problems, the possibilities for acknowledging and promoting the best that individuals, groups and organisations can become will never be fully used. He advocates a positive approach against the background of salutogenisis (a health approach) and psychofortology (a strength perspective). There is a great deal more to be learnt from "doing things right" than from trying to prevent individuals and organisations from repeating previous blunders. Positive psychology has thus broadened the perspective beyond "what is wrong with people" to focus instead on optimal functioning (Luthans, Youssef \& Avolio, 2007).

In the context of the new democratic South Africa, some of the old ways of doing things have become obsolete in the face of new challenges, especially economic and social challenges brought about by labour laws enforcing employment equity, training, capacity building and development. There is a clear relationship between positive feelings and behaviour and the performance of employees (Luthans, 2002) Despite the evidence provided by Avolio and Luthans (2006) and Suthcliffe and Vogus (2003), which shows that average performance is no longer adequate, the organisational behaviour field has thus far paid little attention to managerial and organisational ways to make workplaces conducive to POB.

Since the start of the $21^{\text {st }}$ century, there has been a renewed awakening to the wellness lifestyle phenomenon, where balance and harmony in South Africa are sought after at all levels of existence (Van der Merwe, 2005), which is also transferred into the workplace. POB interlinks well with this concept, as employees want workplaces which reflect an organisational culture in support of their values, ethics and beliefs. The focus has shifted in search of POB elements to which employees can relate as human beings, as they are not human 'doings' (Van der Merwe, 2005).

\section{3}

\section{Clarifying concepts important in this research}

It is important to understand the concepts used in this study to prevent any confusion regarding the focus of this paper. Therefore the concepts positive psychology, positive organisational behaviour (POB), psychological capital (PsyCap) and positive organisational scholarship (POS) are clarified below.

Positive psychology is a wide term with greater use and a broader audience, given that "positive psychology revisits the 'average person' with an interest in finding out what works, what is right, and what is improving" (Sheldon \& King, 2001:216).

Positive organisational behaviour (POB) is defined by Luthans (2002:59) as "the study of positively oriented human resources strengths and psychological capacities that can be measured, developed and effectively managed for performance in contemporary workplaces".

Psychological capital is a positive state-like capacity that has been empirically developed through theory-building and research. Psychological capital is defined as "an individual's positive psychological state of development and is characterised by: having confidence (self efficacy) to take on and put in the necessary effort to succeed at challenging tasks; making a positive attribution (optimism) 
about succeeding now and in the future; persevering toward goals and, when necessary, redirecting paths to goals (hope) in order to succeed; and when beset by problems and adversity, sustaining and bouncing back and even beyond (resilience) to attain success" (Luthans et al., 2006: 387; Luthans, Youssef \& Avolio, 2007: 3). Thus, psychological capital or the PsyCap construct consists of Efficacy, Optimism, Hope and Resilience and, when these are combined in an instrument such as the PCQ, has been shown to represent a second-order core factor construct that predicts performance and satisfaction better than each of the four constituting factors (Luthans, Youssef \& Avolio, 2007).

Positive organisational scholarship (POS) is closely related to POB. The focus in is on collective organisational outcomes, rather than on individuals (Cameron, Dutton \& Quinn, 2003). POS is another discipline focused on positive outcomes, processes, and attributes of organisations and employees (Cameron et al., 2003). Just as positive psychology focuses on exploring optimal individual psychological states rather than pathological ones, according to Cameron et al. (2003), POS focuses the attention on optimal organisational states. Luthans, Youssef and Avolio (2007) support Cameron et al. (2003) in that they argue that positive scientific, work-related initiatives such as POS may also have an organisational impact, although the relationship of POS to performance has not yet been demonstrated. Apart from the obvious link with performance, POS has provided some very valuable perspectives on the positive psychological perspective, such as the dynamics in organisations that lead to the development of human strength and foster resilience in employees, that make healing, restoration and reconciliation possible (Cameron et al., 2003).

The contributors to the field of POS tend to not adopt one particular theory or framework but to draw on the full spectrum of organisational theories to understand, explain and predict the occurrence, causes and consequences of positivity. Luthans, Youssef and Avolio (2007) and Cameron et al. (2003) share an interest in examining enablers, motivation and effects associated with remarkably positive phenomena. They are interested in how they are facilitated, why they work, how they can be identified, and how researchers and managers can capitalize on them. It should be acknowledged that research on both POS and POB have contributed to the vast body of emerging information on positive constructs. Because POB (Luthans, Avolio, Avey \& Norman, 2007) uses a conceptual framework called psychological capital to organise, research propositions, develop measures and translate results for application in practice, in this study it was decided to measure the presence of positive psychological capital in the diverse South African context. Luthans, Avolio et al. (2007) argue strongly that the collective organisational psychological capital capacity is compiled from the sum of individual behaviours in an organisation.

Although there may be many more positive psychological constructs that could be further investigated for future inclusion as psychological capital constructs, the purpose of this study was to only investigate to what extent current psychological capital constructs include Hope, Optimism, Resilience and Selfefficacy, that are applicable within the South African context. To provide a background for the South African context, a brief historical overview is provided, followed by a discussion of the current challenges faced in South Africa.

\section{4}

\section{The South African context}

Since 1994, a large range of political, social and economic changes have occurred in South Africa, but of the most significant challenges facing the country remain, with major repercussions in the workplace. From a political and economic perspective there are several ways to deal with the problems but, thus far, from a societal perspective, the option of taking a positive psychological approach in organisations has been neglected (Luthans et al., 2004). The intention of this contextual overview is to highlight the opportunities and challenges that have arisen from the new democratic dispensation that came into effect from April 1994, with the first fully democratic elections. It aims to show the need for POB practice to foster reconciliation and enhance relationships and performance in a diverse society. The 
current challenges that South Africans are facing are not limited to these issues, and many other countries around the globe are trying to negotiate the difficult path away from fear and despair toward hope and opportunity (Luthans et al., 2004).

Luthans et al. (2004) confirm that the postapartheid organisational culture and business dynamics, with heightened ethnic and language diversity, legally sanctioned affirmative action and its consequences, adverse labour relations with the tendency to open conflict and violence, and the continuing (and increasing) gap between the 'haves' and the 'have nots' in terms of income, education, and opportunities (Roodt, cited by Luthans et al., 2004), is an enormous challenge to deal with.

\subsection{Positive organisational behaviour in South Africa}

In the face of all the negative criticism South Africa has received due to its history, one wonders if it is at all possible for organisations facing such diversity, calamities and social challenges to display POB in terms of Luthans, Youssef and Avolio's (2007) criteria. As previously explained, the purpose of this paper is to explore POB through the psychological capital measure in South African organisations, focussing on HR practitioners.

The four constructs or elements identified by Luthans, Youssef and Avolio (2007), for the purpose of a measurement of developable psychological capital, are Confidence (Selfefficacy), Hope, Optimism and Resilience. On the basis of the literature in support of POB and psychological capital, it can be reasoned that, to enhance organisational performance and improve workplace well-being, if the HR practitioners, who are supposed to be champions or custodians of positive behaviour and facilitators of change, exhibit psychological capital, it should benefit the organisation.

Based on Luthans, Youssef and Avolio's (2007) previous empirical studies on psychological capital, it was decided to explore the applicability of a predominantly Western concept in the South African multi-cultural, multi-racial social context. The researchers applied a positive approach, as suggested by Strümpfer (2005), and expected to find positive levels of $\mathrm{POB}$, as measured in terms of psychological capital, for the HR practitioners registered with the South African Board of People Practices (SABPP). Luthans, Youssef and Avolio's (2007) studies were conducted using American samples. Hence, the research questions applicable to this study were the following:

- To what extent would the concept of psychological capital as measured by the PCQ of Luthans, Youssef et al. (2007) be applicable to human resource practitioners in the South African context?

- What is the level of psychological capital among HR practitioners in South Africa?

- Are there any significant differences between the four factor scales of psychological capital as perceived by HR practitioners based on their demo-graphic profile?

\section{5}

\section{Research method}

This study used a quantitative research methodology. As the independent variable (POB) could not be manipulated, this study may be classified as a non-experimental, ex post facto research design. This study may also be classified as a cross-sectional design (Babbie \& Mouton, 2001), as it is based on an observation of a number of variables (Hope, Self-efficacy [Optimism], Confidence and Resilience) occurring simultaneously, without repeat measures.

\subsection{Sample}

The targeted population was 1500 members of the South African Board of People Practice (SABPP). The SABPP is the accreditation body for HR practitioners in the country. The final sample was 131, representing a response rate of 15 per cent. The demographic data gathered on the participants are reported in Table 1, below.

As can be seen from Table 1, the majority of the participants in this research are male, over the age of 45 years, and Afrikaansspeaking. In terms of ethnicity, White practitioners are in the majority, which reflects the legacy of apartheid. Most of the participants are married, hold a four-year university 
Table 1

Demographic characteristics of the participants

\begin{tabular}{|c|c|c|c|}
\hline Item & Category & Frequency & Percentage \\
\hline Gender & $\begin{array}{l}\text { Male } \\
\text { Female }\end{array}$ & $\begin{array}{l}83 \\
48\end{array}$ & $\begin{array}{l}63.36 \% \\
36.64 \%\end{array}$ \\
\hline Age & $\begin{array}{l}>45 \text { years } \\
<45 \text { years }\end{array}$ & $\begin{array}{l}67 \\
64\end{array}$ & $\begin{array}{l}51.15 \% \\
48.85 \%\end{array}$ \\
\hline Home language & $\begin{array}{l}\text { English } \\
\text { Afrikaans } \\
\text { Other }\end{array}$ & $\begin{array}{l}43 \\
64 \\
23\end{array}$ & $\begin{array}{l}33.08 \% \\
49.23 \% \\
17.69 \%\end{array}$ \\
\hline Ethnicity & $\begin{array}{l}\text { Black } \\
\text { White } \\
\text { Other (Coloured and Asian) }\end{array}$ & $\begin{array}{l}22 \\
98 \\
10\end{array}$ & $\begin{array}{r}16.92 \% \\
75.38 \% \\
7.69 \%\end{array}$ \\
\hline Marital status & $\begin{array}{l}\text { Married } \\
\text { Never married } \\
\text { Other }\end{array}$ & $\begin{array}{l}92 \\
18 \\
21\end{array}$ & $\begin{array}{l}70.23 \% \\
13.74 \% \\
16.03 \%\end{array}$ \\
\hline Educational level & $\begin{array}{l}>2 \text { degrees } \\
1 \text { degree/Honours } \\
\text { Gr } 12 \text { or National Diploma }\end{array}$ & $\begin{array}{l}44 \\
61 \\
25\end{array}$ & $\begin{array}{l}33.85 \% \\
46.92 \% \\
19.23 \%\end{array}$ \\
\hline Years of work experience & $\begin{array}{l}>20 \text { years } \\
11-20 \text { years } \\
1-10 \text { years }\end{array}$ & $\begin{array}{l}48 \\
44 \\
38\end{array}$ & $\begin{array}{l}33.85 \% \\
46.92 \% \\
19.23 \%\end{array}$ \\
\hline Organisational level & $\begin{array}{l}\text { Top management } \\
\text { Professional/Other } \\
\text { Middle management } \\
\text { Non-management }\end{array}$ & $\begin{array}{l}41 \\
32 \\
38 \\
19\end{array}$ & $\begin{array}{l}31.54 \% \\
24.62 \% \\
29.23 \% \\
14.62 \%\end{array}$ \\
\hline Years in organisation & $\begin{array}{l}21-35 \text { years } \\
11-20 \text { years } \\
6-10 \text { years } \\
0-5 \text { years }\end{array}$ & $\begin{array}{l}20 \\
35 \\
30 \\
45\end{array}$ & $\begin{array}{l}15.38 \% \\
26.92 \% \\
23.08 \% \\
34.62 \%\end{array}$ \\
\hline $\begin{array}{l}\text { Level of registration } \\
\text { (SABPP) }\end{array}$ & $\begin{array}{l}\text { Chartered practitioner } \\
\text { HR practitioner } \\
\text { Master practitioner } \\
\text { Other }\end{array}$ & $\begin{array}{l}46 \\
49 \\
18 \\
17\end{array}$ & $\begin{array}{l}35.38 \% \\
37.69 \% \\
13.85 \% \\
13.08 \%\end{array}$ \\
\hline
\end{tabular}

degree and have more than 20 years of work experience. Most of the participants are in top management (31.54 per cent) and can be referred to as master HR practitioners.

\subsection{Measurements}

The psychological capital instrument or questionnaire, also referred to as the PCQ, consists of 24 items. It has four scales (Efficacy, Hope, Resilience and Optimism), each measured by six items. The resulting score represents an individual's level of positive psychological capital (Luthans, Avolio et al., 2007: 209). All constructs are measured on a 6-point Likert scale ranging from 1 (strongly disagree) to 6 (strongly agree). Acceptable Cronbach alphas were found for the PCQ in previous studies ranging from 0.88 to 0.89 (see Luthans, Avolio et al., 2007: 209).

The PCQ was administered in English to South African participants via the internet.
Each participant could submit only one completed questionnaire. Biographical information on each participant's gender, home language, qualification, race/ethnicity, marital status, age and work experience was also collected. Anonymity and confidentiality were ensured.

\subsection{Data analysis}

The statistical analysis in this study was carried out using the SAS and SPSS program. The frequency procedure was applied to measure the demographic variables of age, race/ethnicity, gender, language, marital status, seniority level, educational level, professional level, years of experience and years in position. The reliability and validity of the PCQ were determined by means of Cronbach's alpha coefficients, as well as exploratory factor analysis. The Pearson product-moment correlation coefficient was used to specify the relationship 
between the PCQ items and dimensions. Multivariate analysis of variance (MANOVA) was used to determine the significance of differences between the psychological capital dimensions and demographic variables. For most of the analyses, three racial ethnic categories were used, namely Whites, Blacks and Asians/ Coloureds.

\section{6}

\section{Results and findings}

\subsection{Factor analysis}

The responses collected from the 24 questions in the PCQ were computed to establish if there were sufficient inter-correlations between the dependent variables (Confidence, Hope,
Optimism, Resilience) to provide support for applicability of the four constructs for the specific sample. The values, as established by means of the Initial Factor method: principal components, yielded the eigenvalues which are indicated in the correlation matrix in Table 2, below.

The general convention is that only factors with eigenvalues greater than one should be considered meaningful factors (Terre Blanche \& Durrheim, 1999).

From Table 2 it is evident that six possible factors could be retained in terms of the MINEIGEN criterion, with values greater than one. This result is in contrast with Luthans, Youssef and Avolio's (2007) original PCQ design, which consists of four factors. The first four factors cumulatively account for $54 \%$ of

Table 2

Factor analysis initial factor method: principal components

\begin{tabular}{|c|c|c|c|c|}
\hline Component & Eigenvalues & Difference & Proportion & Cumulative \% \\
\hline 1 & 8.04749314 & 6.02318065 & 0.3353 & 0.3353 \\
\hline 2 & 2.02431249 & 0.38655119 & 0.0843 & 0.4196 \\
\hline 3 & 1.63776130 & 0.28815664 & 0.0682 & 0.4879 \\
\hline 4 & 1.34960466 & 0.18022684 & 0.0562 & 0.5441 \\
\hline 5 & 1.16937782 & 0.16216168 & 0.0487 & 0.5928 \\
\hline 6 & 1.00721614 & 0.06077189 & 0.0420 & 0.6348 \\
\hline 7 & 0.94644425 & 0.08239399 & 0.0394 & 0.6742 \\
\hline 8 & 0.86405026 & 0.06440617 & 0.0360 & 0.7102 \\
\hline 9 & 0.79964409 & 0.07166556 & 0.0333 & 0.7436 \\
\hline 10 & 0.72797853 & 0.03745792 & 0.0303 & 0.7739 \\
\hline 11 & 0.69052061 & 0.03093884 & 0.0288 & 0.8027 \\
\hline 12 & 0.65958177 & 0.05729373 & 0.0275 & 0.8302 \\
\hline 13 & 0.60228804 & 0.06500054 & 0.0251 & 0.8552 \\
\hline 14 & 0.53728750 & 0.04576077 & 0.0224 & 0.8776 \\
\hline 15 & 0.49152673 & 0.09976529 & 0.0205 & 0.8981 \\
\hline 16 & 0.39176144 & 0.00138330 & 0.0163 & 0.9144 \\
\hline 17 & 0.39037814 & 0.05470746 & 0.0163 & 0.9307 \\
\hline 18 & 0.33567068 & 0.05332581 & 0.0140 & 0.9447 \\
\hline 19 & 0.28234487 & 0.02032829 & 0.0118 & 0.9565 \\
\hline 20 & 0.26201658 & 0.02182078 & 0.0109 & 0.9674 \\
\hline 21 & 0.24019580 & 0.01781359 & 0.0100 & 0.9774 \\
\hline 22 & 0.22238221 & 0.05380400 & 0.0093 & 0.9866 \\
\hline 23 & 0.16857821 & 0.01699348 & 0.0070 & 0.9937 \\
\hline 24 & 0.15158473 & & 0.0063 & 1.0000 \\
\hline
\end{tabular}


the total variance and are accepted as the summarising factors which will be further explored. Although Factors 5 and 6 have eigenvalues higher than one, these factors could not be interpreted and are therefore not further pursued.

Once the factors had been determined, these factors were rotated to achieve a more interpretable structure (Terre Blanche \&
Durrheim, 1999). The Orthogonal rotation method, applied next, was based on the assumption that factors were uncorrelated. The resulting Orthogonal transformation matrix would yield either support for, or evidence against, Luthans, Youssef and Avolio's (2007) and Luthans, Avolio et al.'s (2007) constructs. The results are reported in Table 3 , below.

From Table 3 it is evident that some of the

Table 3

Orthogonal transformation matrix

\begin{tabular}{|c|c|c|c|c|}
\hline Factor & 1 & 2 & 3 & 4 \\
\hline $\mathbf{1}$ & $\mathbf{0 . 7 1}$ & 0.47 & 0.41 & 0.32 \\
$\mathbf{2}$ & -0.58 & $\mathbf{0 . 5 6}$ & 0.54 & -0.22 \\
$\mathbf{3}$ & 0.04 & -0.68 & $\mathbf{0 . 7 3}$ & -0.04 \\
$\mathbf{4}$ & -0.38 & -0.06 & 0.01 & $\mathbf{0 . 9 2}$ \\
\hline
\end{tabular}

factors correlated negatively. Therefore a fourfactor structure for the PCQ in this study did not make sense. Correlation coefficients, called factor loadings, indicate the relationship between the items and the factors. Reverse scoring was accurately completed on Items 4, 7 and 10 as per the original design of the PCQ. The ideal solution would be that each item only correlates with one factor; however, this was not the case. From the factor loadings, it was clear that some of the items loaded onto the wrong factor, as indicated in Table 4, below.

Conceptually sound interpretations based on the results in Table 4 could not be made and it was decided to repeat the factor analysis for three factors, as indicated by the data. For ease of use, these factors were renamed, based on the dimensions, with high loadings on the factors: Hopeful-Confidence (HC), Resilience(R),

\section{Table 4}

Rotated factor pattern for PSA-PsyCap (4-Factor)

\begin{tabular}{|l|r|r|r|r|r|}
\hline \multicolumn{1}{|c|}{ Construct } & Component & Factor 1 & Factor 2 & Factor 3 & Factor 4 \\
\hline & PCQ20 & $\mathbf{0 . 7 1 6 2 6}$ & 0.30605 & 0.05708 & 0.25930 \\
& PCQ 5 & $\mathbf{0 . 7 0 0 4 3}$ & 0.32622 & 0.07558 & 0.06341 \\
& PCQ21 & $\mathbf{0 . 6 8 2 9 0}$ & 0.03393 & 0.27445 & 0.19784 \\
& PCQ24 & $\mathbf{0 . 6 7 8 7 5}$ & 0.38158 & -0.17144 & 0.32415 \\
Confidence/ Hope & PCQ14 & $\mathbf{0 . 6 7 1 0 7}$ & -0.01845 & 0.30049 & 0.04669 \\
& PCQ16 & $\mathbf{0 . 6 4 2 6 2}$ & 0.10263 & 0.38629 & 0.10053 \\
& PCQ15 & $\mathbf{0 . 6 3 1 7 8}$ & 0.33726 & 0.05451 & 0.24882 \\
& PCQ17 & $\mathbf{0 . 5 5 9 4 5}$ & 0.036191 & -0.13236 & 0.38450 \\
& PCQ19 & $\mathbf{0 . 5 3 6 8 4}$ & -0.00473 & 0.48179 & 0.28591 \\
& PCQ6 & $\mathbf{0 . 4 9 8 1 3}$ & -0.02828 & -0.00946 & -0.03085 \\
& PCQ8 & $\mathbf{0 . 4 8 2 7 4}$ & 0.19076 & 0.46123 & 0.01038 \\
\hline Hope & PCQ2 & -0.08894 & 0.78778 & 0.12162 & 0.12260 \\
& PCQ23 & 0.32037 & $\mathbf{0 . 7 5 2 3 4}$ & 0.13843 & 0.10729 \\
& PCQ22 & 0.16214 & $\mathbf{0 . 7 0 1 3 0}$ & 0.41139 & 0.00005 \\
& PCQ3 & 0.41653 & $\mathbf{0 . 6 0 9 3 1}$ & 0.20644 & -0.12772 \\
& RPCQ4 & 0.23305 & $\mathbf{0 . 4 6 5 8 9}$ & 0.17760 & 0.23103 \\
\hline \multirow{5}{*}{ Resilience } & PCQ12 & 0.12775 & 0.06184 & $\mathbf{0 . 6 6 7 9 7}$ & 0.28558 \\
& PCQ11 & -0.04382 & 0.23505 & $\mathbf{0 . 6 2 2 5 7}$ & 0.12772 \\
& PCQ1 & -0.05884 & 0.37042 & $\mathbf{0 . 5 5 2 4 5}$ & -0.10452 \\
& PCQ13 & 0.38067 & 0.18965 & $\mathbf{0 . 5 3 0 2 5}$ & -0.03756 \\
\hline \multirow{5}{*}{ Optimism } & PCQ18 & 0.38751 & 0.10370 & $\mathbf{0 . 5 0 4 8 3}$ & 0.30722 \\
\hline & RPCQ10 & 0.10519 & 0.04440 & 0.04099 & $\mathbf{0 . 7 1 5 9 6}$ \\
& RPCQ7 & 0.04152 & 0.16772 & 0.10386 & $\mathbf{0 . 6 9 2 8 8}$ \\
& PCQ9 & 0.18491 & 0.01145 & 0.16988 & $\mathbf{0 . 5 1 2 6 7}$ \\
\hline
\end{tabular}


and Optimism $(\mathrm{O})$. Because of the conclusion that the sample did not differentiate between Confidence and Hope, these constructs were combined to form Hopeful-Confidence (HC). The results of the rotated three-factor pattern are reported in Table 5, below.

Although some of the questionnaire items continued to have multiple loadings on factors, this result should be considered a synergetic effect of the constructs, where all have a

Table 5

Rotated factor pattern for PSA-PsyCap (3-Factor)

\begin{tabular}{|l|c|c|c|c|}
\hline Construct & Component & Factor 1 & Factor 2 & Factor 3 \\
\hline & PCQ24 & $\mathbf{0 . 7 9}$ & -0.08 & 0.34 \\
& PCQ20 & $\mathbf{0 . 7 6}$ & 0.15 & 0.27 \\
& PCQ17 & $\mathbf{0 . 6 9}$ & -0.06 & 0.33 \\
Hopeful/ & PCQ15 & $\mathbf{0 . 6 8}$ & 0.13 & 0.31 \\
Confidence & PCQ5 & $\mathbf{0 . 6 7}$ & 0.16 & 0.29 \\
& PCQ21 & $\mathbf{0 . 6 6}$ & 0.37 & 0.02 \\
& PCQ14 & $\mathbf{0 . 5 9}$ & 0.39 & -0.04 \\
& PCQ16 & $\mathbf{0 . 5 8}$ & 0.47 & 0.09 \\
& PCQ6 & $\mathbf{0 . 4 4}$ & 0.06 & -0.06 \\
& RPCQ10 & $\mathbf{0 . 3 7}$ & 0.08 & 0.07 \\
& PCQ9 & $\mathbf{0 . 3 4}$ & 0.21 & 0.20 \\
\hline & RPCQ7 & $\mathbf{0 . 3 0}$ & 0.12 & 0.11 \\
& PCQ12 & 0.14 & $\mathbf{0 . 6 8}$ & 0.28 \\
& PCQ11 & -0.07 & $\mathbf{0 . 6 0}$ & 0.20 \\
& PCQ13 & 0.27 & $\mathbf{0 . 5 6}$ & 0.01 \\
& PCQ19 & 0.53 & $\mathbf{0 . 5 6}$ & 0.12 \\
& PCQ18 & 0.40 & $\mathbf{0 . 5 6}$ & 0.19 \\
& PCQ8 & 0.39 & $\mathbf{0 . 5 1}$ & 0.40 \\
\hline & PCQ1 & -0.15 & $\mathbf{0 . 5 1}$ & $\mathbf{0 . 8 0}$ \\
& PCQ2 & 0.01 & 0.07 & $\mathbf{0 . 7 4}$ \\
& PCQ23 & 0.35 & 0.15 & $\mathbf{0 . 7 2}$ \\
& PCQ22 & 0.13 & 0.39 & $\mathbf{0 . 5 9}$ \\
& PCQ3 & 0.38 & 0.22 & $\mathbf{0 . 4 7}$ \\
\hline
\end{tabular}

reciprocal effect on one another. Luthans, Youssef and Avolio (2007) refer to the synergetic effect and propose that the whole (Psychological Capital) is greater than the sum of its descriptive parts. In this study, the synergetic effect may have been more prominent because of the sample size. If one is "hopefully-confident" in achieving success, one's attitude will generally be optimistic regarding the future, and one will be resilient when faced by adverse conditions.

Clearly then, the factor structure of the PSA-PsyCap instrument in this research does not compare fully with the four-factor structure of the PCQ designed by Luthans, Youssef and Avolio (2007). This study does not question the discriminant validity of the original PCQ constructs, but explores how these constructs are represented in a specific South African sample; and finally, what meaning can be extracted from the interaction between psychological capital factors in a new context.

Lemke and Wiersma (1976) state that construct validity is confirmed when the obtained factors have a useful meaning. For the purposes of this study, it can now be confirmed that PSA-PsyCap factors have a useful meaning and were usable for further investigation. The investigation was continued by conducting a correlation analysis.

A Pearson correlation procedure was performed to determine the strength of the relationship with the factor dimension allocated to it. The Pearson correlation coefficient results $(r)$ among the various PSA-PsyCap instrument items making up a construct are depicted in Table 6, below.

It is clear that the dependent variables, as categorized for the PSA-PsyCap instrument, correlated positively with each other, as no negative $r$-values were detected. The descriptive statistics and reliabilities of the three-factor structure for the PSA-PsyCap instrument are reported in Table 7, below.

Table 7 shows that the factors of the PSAPsyCap instrument are normally distributed in 
Table 6

Pearson correlation coefficients for Psa-PsyCap factors

\begin{tabular}{|c|c|c|c|c|c|c|c|c|c|c|c|c|}
\hline \multicolumn{13}{|c|}{ Hopeful-Confidence ( $n=131)$} \\
\hline PsyCap & 5 & 6 & 7 & 9 & 10 & 14 & 15 & 16 & 17 & 20 & 21 & 24 \\
\hline 5 & 1.00 & 0.421 & 0.196 & 0.280 & 0.147 & 0.519 & 0.511 & 0.417 & 0.452 & 0.585 & 0.430 & 0.605 \\
\hline 6 & 0.421 & 1.00 & 0.038 & 0.232 & 0.042 & 0.259 & 0.293 & 0.146 & 0.153 & 0.271 & 0.204 & 0.223 \\
\hline 7 & 0.196 & 0.038 & 1.00 & 0.197 & 0.329 & 0.159 & 0.266 & 0.159 & 0.307 & 0.241 & 0.153 & 0.226 \\
\hline 9 & 0.280 & 0.232 & 0.197 & 1.00 & 0.240 & 0.228 & 0.328 & 0.179 & 0.200 & 0.250 & 0.240 & 0.216 \\
\hline 10 & 0.147 & 0.422 & 0.329 & 0.240 & 1.00 & 0.115 & 0.199 & 0.188 & 0.297 & 0.279 & 0.241 & 0.288 \\
\hline 14 & 0.519 & 0.259 & 0.159 & 0.228 & 0.115 & 1.00 & 0.407 & 0.554 & 0.307 & 0.371 & 0.429 & 0.439 \\
\hline 15 & 0.511 & 0.293 & 0.266 & 0.328 & 0.199 & 0.407 & 1.00 & 0.574 & 0.487 & 0.640 & 0.470 & 0.527 \\
\hline 16 & 0.417 & 0.146 & 0.159 & 0.179 & 0.188 & 0.554 & 0.574 & 1.00 & 0.363 & 0.473 & 0.524 & 0.402 \\
\hline 17 & 0.452 & 0.153 & 0.307 & 0.200 & 0.297 & 0.307 & 0.487 & 0.363 & 1.00 & 0.554 & 0.384 & 0.681 \\
\hline 20 & 0.585 & 0.271 & 0.241 & 0.250 & 0.279 & 0.371 & 0.640 & 0.473 & 0.554 & 1.00 & 0.674 & 0.627 \\
\hline 21 & 0.430 & 0.204 & 0.153 & 0.240 & 0.241 & 0.429 & 0.470 & 0.524 & 0.384 & 0.674 & 1.00 & 0.534 \\
\hline 24 & 0.605 & 0.223 & 0.226 & 0.216 & 0.288 & 0.439 & 0.527 & 0.402 & 0.681 & 0.627 & 0.534 & 1.00 \\
\hline \multicolumn{13}{|c|}{ Optimism } \\
\hline PsyCap & \multicolumn{2}{|l|}{1} & \multicolumn{2}{|l|}{8} & 11 & \multicolumn{2}{|c|}{12} & \multicolumn{2}{|l|}{13} & 18 & \multicolumn{2}{|c|}{19} \\
\hline 1 & \multicolumn{2}{|l|}{1.00} & \multicolumn{2}{|l|}{0.370} & 0.292 & \multicolumn{2}{|c|}{0.270} & \multicolumn{2}{|l|}{0.247} & 0.192 & \multicolumn{2}{|c|}{0.126} \\
\hline 8 & \multicolumn{2}{|c|}{0.370} & \multicolumn{2}{|l|}{1.00} & 0.171 & \multicolumn{2}{|c|}{0.345} & \multicolumn{2}{|l|}{0.400} & 0.342 & \multicolumn{2}{|c|}{0.455} \\
\hline 11 & \multicolumn{2}{|c|}{0.293} & \multicolumn{2}{|l|}{0.171} & 1.00 & \multicolumn{2}{|c|}{0.328} & \multicolumn{2}{|l|}{0.347} & 0.314 & & 301 \\
\hline 12 & 0.27 & & 0.345 & & 0.328 & 1.0 & & 0.381 & & 0.401 & & 392 \\
\hline 13 & 0.247 & & 0.400 & & 0.347 & 0.3 & & 1.00 & & 0.276 & & 340 \\
\hline 18 & 0.192 & & 0.342 & & 0.314 & 0.4 & & 0.276 & & 1.00 & & 607 \\
\hline 19 & 0.126 & & 0.455 & & 0.301 & 0.3 & & 0.340 & & 0.607 & & .00 \\
\hline & & & & & & silience & & & & & & \\
\hline PsyCap & & 2 & & 3 & & 4 & & & 22 & & 23 & \\
\hline 2 & & .00 & & 0.416 & & & & & 0.461 & & 0.50 & \\
\hline 3 & & .416 & & 1.00 & & & & & 0.524 & & $0.5 c$ & \\
\hline 4 & & .285 & & 0.322 & & 1. & & & 0.423 & & 0.47 & \\
\hline 22 & & .461 & & 0.524 & & & & & 1.00 & & 0.67 & \\
\hline 23 & & .509 & & 0.508 & & & & & 0.672 & & $1.0 \mathrm{C}$ & \\
\hline
\end{tabular}

Table 7

Descriptive statistics and reliabilities of the PSA-PsyCap

\begin{tabular}{|l|c|c|c|c|c|}
\hline & Mean & SD & Skewness & Kurtosis & A \\
\hline Hopeful-Confidence & 4.839 & 1.016 & -1.048 & 1.073 & 0.86 \\
Optimism & 4.895 & 0.917 & -0.770 & 0.442 & 0.77 \\
Resilience & 4.490 & 1.177 & -0.908 & 0.614 & 0.81 \\
\hline
\end{tabular}

the sample, with low skewness and kurtosis. The Cronbach's alpha coefficients compare well with the guideline of 0.70 , demonstrating that a large portion of variance is explained by the dimension (internal consistency of the dimensions), as recommended by Nunnally and Bernstein (1994). From the mean scores, it is evident that the HR practitioners display a high level of Hopeful-Confidence, Resilience and Optimism, which answers one of the research questions.
Based on the preceding analysis, the PSAPsyCap instrument's dependent variables were now considered acceptable for individual analysis.

\subsection{Multivariate analysis of variance}

Next, a MANOVA was done to assess the relationship between the PSA-PsyCap dimensions (Hopeful-Confidence, Optimism and Resilience) and demographic variables such as age, race/ ethnicity, gender, language, marital 
status, seniority level, qualification, professsional level, years in position and years of experience. These demographic variables were first analysed for statistical significance using Wilk's lambda statistics. The results of these comparisons are reported in Table 8, below.

From this table it is evident that statistically significant differences exist only for age, ethnicity, language, marital status, position, qualification and the PSA-PsyCap instrument's dimensions. The results show no statistically significant differences for gender, level of professional registration, years in position, and years of work experience. The results of the significant relationships were further explored by determining the effect size. Effect size

Table 8

MANOVAs: Wilk's lambda demographic variables and the PSA-PsyCap dimensions

\begin{tabular}{|l|c|c|c|c|c|c|}
\hline \multicolumn{1}{|c|}{ Demographic variable } & Value & F & df & Error df & Sig. & $\begin{array}{c}\text { Partial Eta } \\
\text { Squared }\end{array}$ \\
\hline Age & 0.965 & $1.519 \mathrm{a}$ & 3.000 & 126.000 & 0.213 & 0.035 \\
Race/ethnicity & 0.878 & $2.813^{\mathrm{a}}$ & 6.000 & 250.000 & 0.011 & $0.063^{*}$ \\
Gender & 0.969 & $1.327^{\mathrm{a}}$ & 3.000 & 126.000 & 0.269 & 0.031 \\
Language & 0.877 & $2.829 \mathrm{a}$ & 6.000 & 250.000 & 0.011 & $0.064^{*}$ \\
Marital status & 0.885 & $2.632^{\mathrm{a}}$ & 6.000 & 250.000 & 0.017 & $0.059^{*}$ \\
Seniority level & 0.813 & 2.971 & 9.000 & 301.934 & 0.002 & $0.067^{*}$ \\
Qualification & 0.885 & $2.615^{\mathrm{a}}$ & 6.000 & 250.000 & 0.018 & $0.059^{*}$ \\
Professional level & 0.922 & 1.138 & 9.000 & 301.934 & 0.335 & 0.027 \\
Years in position & 0.952 & $1.034^{\mathrm{a}}$ & 6.000 & 250.000 & 0.404 & 0.024 \\
Years of work experience & 0.971 & 0.409 & 9.000 & 301.934 & 0.930 & 0.010 \\
\hline
\end{tabular}

indicates the magnitude of a finding. Cohen's (1988) classification of effect sizes has become a standard in social research: 0.01 is small, 0.09 is medium, and 0.25 is a large effect size. The results of the significant relationships between the demographic variables and the PSA-PsyCap instrument's dimensions are reported below:

- The Wilk's lambda for age is equal to $0.965[F(3,126)=1.519, p=0.213]$. This is not statistically significant, as $p>0.05$, and implies that, overall, there is no significant difference between the mean scores of the groups relating to age and the three dimensions of the PSA-PsyCap instrument. The test of between-subject effect shows that there is a statistically significant difference between the age groups based on Hopeful-Confidence. On average, the group aged 45 years and older scored higher on this dimension than practitioners aged 45 years and younger. However, the effect size yielded an eta of 0.034 , which is considered a small effect size.

- The Wilk's lambda for race/ethnicity is equal to $0.878[F(6,250)=2.813, p=$ $0.011]$. This is statistically significant, as $p<0.05$, and implies that there is significant difference between the mean scores of the various race/ethnic groups relating to the three dimensions of the PSA-PsyCap instrument. Further analysis showed that statistically significant differences exist between Black and White groups in terms of Hopeful-Confidence ( $p$ $=0.042)$. On average, the White ethnic group scored higher on HopefulConfidence than the Black ethnic group (mean difference $=3.6085$ ). The effect size yielded an eta of 0.065 , which is considered a small effect size.

- The Wilk's lambda for home language is equal to $0.877[F(6,250)=2.813, p=$ $0.011]$. This is statistically significant, as $p<0.05$, and implies that there are significant differences between the mean scores of the groups relating to language and the three dimensions of the PSAPsyCap instrument. Further post hoc analysis showed that statistically signifycant differences exist between the Afrikaans-speaking group (predominantly White) and the speakers of traditional languages of the other race/ethnic groups in terms of 
resilience $(p=0.019)$. On average, the latter group reported significantly higher levels of resilience than practi-tioners with Afrikaans as their home language (mean difference $=2.712$ ). The effect size yielded an eta of 0.063 , which is considered a small effect size. No statistically significant differences were found for the PSAPsyCap instrument's dimensions and practitioners with English as their home language.

- The Wilk's lambda for marital status is equal to $0.885[F(6,250)=2.632, p=$ $0.017]$. This is statistically significant, as $p<0.05$, and implies that there are significant differences between the mean scores of the groups based on marital status and the three dimensions of the PSAPsyCap instrument. Further post hoc analysis showed that statistically significant differences $(p=0.001)$ exist between practitioners who have never been married and others (i.e. widowed, divorced, estranged, co-habiting) in terms of Optimism. On average, practitioners who have never been married reported significantly lower levels of optimism than practitioners in the other marital status categories (mean difference $=4.57)$. The effect size yielded an eta of 0.114 , which is considered a medium effect size. No statistically significant differences were found for practitioners who were married and the three dimensions of the PSA-PsyCap instrument.

- The Wilk's lambda for seniority level is equal to $0.813[F(9,301.934)=2.971, p=$ $0.002]$. This is statistically significant, as $p<0.05$, and implies that there are significant differences between the mean scores of the groups relating to seniority level and the three dimensions of the PSAPsyCap instrument. Further post hoc analysis showed that statistically significant differences exist between top management and professionals with respect to the Hopeful-Confidence $(p=0.01)$, Optimism $(p=0.01)$ and Resilience $(p=0.05)$ dimensions. On average, top management scored significantly higher on all three dimensions than professionals. The mean differences for the two groups based on the PSAPsyCap dimensions were as follows:
Hopeful-Confidence (4.43), Optimism (2.82) and Resilience (2.46). The effect sizes were as follows: Hopeful-Confidence $(p=0.11)$, Optimism $(\mathrm{p}=0.10)$ and Resilience $(\mathrm{p}=0.06)$. The mean differences of the two groups based on Hopeful-Confidence and Optimism yielded medium effects, whereas the effect size of Resilience yielded a small effect size.

- The Wilk's lambda for qualification is equal to $0.885[F(6,250)=2.615, p=$ $0.018]$. This is statistically significant, as $p<0.05$, and implies that there are significant differences between the mean scores of the groups based on qualifications and the three dimensions of the PSAPsyCap instrument. Further post hoc analysis showed a statistically significant difference $(p=0.026)$ between practitioners with an undergraduate degree and those with graduate degrees with respect to Optimism. On average, practitioners with a graduate degree reported significantly higher levels of Optimism than practitioners with only undergraduate degrees (mean difference $=2.032$ ). The effect size yielded an eta of 0.048 , which is considered a small effect size.

\section{7}

\section{Discussion and conclusion}

POB is the study of positively oriented human resources strengths and psychological capacities that can be measured, developed and effectively managed for performance in contemporary workplaces (Luthans, 2002; Luthans, Youssef \& Avolio, 2007; Luthans, Avolio et al. 2007). The objective of this study was to explore whether South African HR practitioners embrace the elements of $\mathrm{POB}$, as described by Luthans and colleagues and to determine to what extent the PCQ constructs of Hope, Self-efficacy (Confidence), Optimism and Resilience were present. The data were analysed in order to examine the applicability of Psychological Capital and POB theory (Luthans, Youssef \& Avolio, 2007; Luthans, Avolio et al. 2007) to the unique South African context. The discussion is done per research question. 
Research Question 1: To what extent would the concept of psychological capital as measured by the PCQ of Luthans, Youssef et al. (2007) be applicable to human resource practitioners in the South African context?

A principal component factor analysis resulted in a three-factor structure for the PSA-PsyCap instrument. The participants in this sample perceived Hope and Confidence (Self-efficacy) as the same construct. As a result, the three factors were labelled Hopeful-Confidence, Optimism and Resilience. All three factors showed acceptable internal consistency. These results are different from those of previous studies, which identified a four-factor construct (Luthans, Youssef \& Avolio, 2007; Luthans, Avolio et al. 2007). Hopeful-Confidence, Optimism and Resilience thus seems more relevant as constructs in the South African sample.

Research Question 2: What is the level of psychological capital among HR practitioners in South Africa?

The results of the research showed that the HR practitioners display a high level of HopefulConfidence, Resilience and Optimism. The fact that HR practitioners exhibit a positive psychological capital in South Africa is a reassuring finding. It supports the assumption made by the researchers that HR practitioners should have a higher level of psychological capital to fulfil their expected role in a diverse new democracy. HR management practices have been found to positively influence an organisation's performance and thus function as a potential source of competitive advantage for organisations. This research therefore strengthens the case that South African HR practitioners and managers should fully embrace psychological capital, to effectively create caring workplaces that take cognizance of the broader economic and social issues affecting employees.

Research Question 3: Are there any significant differences between the four factor scales of psychological capital as perceived by HR practitioners based on their demographic profile?

Results showed significant differences in the three factors in terms of demographic variables. In this research, master practitioners in top management reported significantly higher levels of Hopeful-Confidence, Optimism and Resilience than practitioners in the lower organisational levels. Based on the statistical evidence, it can be argued that participants with high levels of psychological capital occupy more senior positions. It is not clear if South African Psychological Capital stems from the status of the position, or if it is the result of achieving it, despite adverse pressures. This is a phenomenon worth investigating by means of qualitative research and correlation studies. The results also showed that HR practitioners with graduate degrees were significantly more optimistic than those with only an undergraduate degree. One possible explanation can be found in the fact that the more highly educated people in this study were found in more top level positions, which in this case also reported higher levels of optimism.

This finding bodes well in terms of the leadership role that master (senior) practitioners can play in creating hope in the workplace. As those responsible for leading employment equity, affirmative action and other corrective initiatives in the South African workplace, HR practitioners should not only "buy into" these initiatives and support them, but they have to champion them. The extent to which they embrace the tenets of positive organisational behaviour may, in the end, influence the success of workplace change and also South Africa's ability to transform social and economic realities for the majority of its population.

The results showed that practitioners aged 45 years and older scored higher on HopefulConfidence than practitioners aged 45 years and younger. It is worth mentioning that more than half the participants were under the age of 45 years. The effect of affirmative action and employment equity legislation in the new democracy has resulted in higher job competetion among younger practitioners.

White respondents scored significantly higher on Hopeful-Confidence than Blacks. This result was puzzling. In the new dispensation since 1994, Blacks have gained political power and one would expect them to be more hopeful and confident about the future than Whites, who have in general lost political 
power. However, the reality in the workplace is that Whites still dominate the top positions and Blacks are gradually gaining access to better positions (Booysen, 2007; Nkomo, 2007). Another possible explanation is that the Whites who remain in South Africa are hopeful and confident, compared to those who have emigrated. All of these possibilities need to be subjected to further study.

Home language also appeared to be a differentiator in terms of the three factors. In many ways, in South Africa, language is a proxy for the racial/ethnic category. Practitioners with traditional Black home languages scored higher on Resilience compared to practitioners whose home language is Afrikaans. Historically, the former group exhibited Resilience largely in the face of apartheid oppression. In one sense, the results reflected the impact of both the past and present realities in South Africa. For HR practitioners in a new democracy comprising complex diversity such as South Africa, psychological capital can be the binding force for compassion and passion, but it also means that HR practitioners and managers must dare to care and not hide behind the past or resist the future.

As with all studies, there are limitations to this study. The relatively small sample size due to a limited response rate for this study was less than desired. However, the demographic profile of the sample is representative of the current equity profile in professional and managerial positions in South Africa. The results however cannot be generalised to the total population.

Future studies should endeavour to use a larger sample size. Nevertheless, the results shed some light on the applicability of POB and validity of Psychological Capital within South Africa's diverse context. Psychological capital, if present and practiced by all not just by the HR practitioners, could benefit the organisation and country as a whole especially during turmoil or change. The results of the research also suggest the need to test POB constructs and psychological capital in different social and cultural contexts, as well as attending to a country's internal diversity.

\section{Acknowledgement}

The authors would like to thank the South African Board of People Practice (SABPP) and Ms Barbara Grobbelaar for their assistance in the data collection.

\section{References}

AVOLIO, B.J. \& LUTHANS, F. 2006. The high impact leader: moments matter in accelerating authentic leadership development. New York: McGraw-Hill.

BABBIE, E. \& MOUTON, J. 2001. The practice of social research. New York: Oxford University Press. BOOYSEN, L. 2007. Societal power shifts and changing social identities in South Africa: workplace implications. Southern African Journal of Economic and Management Sciences, 10(1):1-20.

CAMERON, K., DUTTON, J.E. \& QUINN, R.E. 2003. Positive organizational scholarship: foundations of a new Discipline. San Francisco: Berrett-Koehler.

COHEN, J. 1988. Statistical power analysis for the behavioral sciences (2nd ed.) Hillsdale, NJ: Lawrence Erlbaum.

DU PLESSIS, Y. \& BARKHUIZEN, E.N. 2011. Strategic role of human resource professionals in a South African context. Paper presented at the $15^{\text {th }}$ European Association of Work and Organisational Psychology Conference, Maastricht, The Netherlands, 25-28 May.

LEMKE E. \& WIERSMA, W. 1976. Principles of psychological measurement. Boston, MA: Houghton Mifflin.

LUTHANS, F. 2002. Positive organizational behaviour: Developing and managing psychological strengths. Academy of Management Executive, 16(1):57-75.

LUTHANS, F., VAN WYK, R. \& WALUMBA, F.O. 2004. Recognition and development of hope for South African organizational leaders. Leadership and Organization Development Journal, 25(6):512-527.

LUTHANS, F., AVEY, J.B., AVOLIO, B.J., NORMAN, S.M. \& COMBS, G.M. 2006. Psychological capital development: Toward a micro-intervention. Journal of Organizational Behavior, 27:387-393. 
LUTHANS, F., AVOLIO, B.J., AVEY, J.B. \& NORMAN, S.M. 2007. Positive psychological capital: measurement and relationship with performance and satisfaction. Personnel Psychology, 60:541-572. LUTHANS, F., YOUSSEF, C.M. \& AVOLIO, B.J. 2007. Psychological capital: developing the human competitive edge. New York: Oxford University Press.

NKOMO, S.M. 2007. Workplace Diversity Management: Issues, Controversies and Practices. South African Journal of Labour Relations, 31(2):6-9.

NUNNALLY, J.C. \& BERNSTEIN, I. H. 1994. Psychometric theory ( $3^{\text {rd }}$ ed.) New York: McGraw-Hill. PETERSON, C. \& SELIGMAN, M. 2004. Character strengths and virtues: A handbook and classification. New York: Oxford University Press.

ROBERTS, L.M. 2006. Shifting the lens on organizational life: The added value of positive scholarship. Academy of Management Review, 31(2):292-305.

SELIGMAN, M.E.P. \& CSIKSZENTMIHALYI, M. 2000. Positive psychology: An introduction. American Psychologist, 55(1):5-14.

SHELDON, K. \& KING, L. 2001. Why positive psychology is necessary. American Psychologist, 56: 216-217.

STRÜMPFER, D.J.W. 2005. Standing on the shoulders of giants: Notes on early Positive Psychology (Psychofortology). South African Journal of Psychology, 35(1):21-45.

SUTHCLIFFE, K.M. \& VOGUS, T. 2003. Organizing for resilience. In K.S. Cameron, J.E., Dutton \& R.E. Quinn (eds.) Positive organizational scholarship. San Francisco: Berrett-Koehler, 94-110.

TERRE BLANCHE, M. \& DURRHEIM, K. 1999. Research in practice: Applied methods for the social sciences. Cape Town: University of Cape Town Press.

VAN DER MERWE, A. 2005. Health and happiness. HSM Publishers 